\title{
Designing and Using Digital Games as Historical Learning Con- texts for Primary School Classrooms
}

\author{
Juan Hiriart \\ j.f.v.hiriart@salford.ac.uk \\ School of Arts and Media \\ University of Salford
}

History and games have a long and well documented relationship. From early conflict-based board games such as Wei Hai and Chaturanga, played respectively in China and India over two millennia ago, board games evolved into highly sophisticated digital games based on historical settings, conflicts or events. Despite the growing academic interest in using these technologies for historical education, evidenced by a growing number of publications and conferences dedicated to this subject, it can still be argued that key issues regarding their representational appropriateness, educational effectiveness and practical implementation in formal educational settings remain unclear. What are the main benefits of video games as historical learning contexts? How can video games be successfully integrated and used as a educational resources in formal educational environments?

This chapter gives an overview of a $\mathrm{PhD}$ research project which attempts to answer these questions. The project adopted an action-research approach, relying on the iterative development of a series of historical game prototypes built with the intention of representing life in Anglo-Saxon Britain, after the departure of the Romans around AD410. During their development, the prototypes were presented and critically analysed by historians, archaeologists and history educators, moving to its implementation in a primary school classroom at a later stage.

This chapter is structured in the following way. First, the development process of the game prototypes is described, highlighting some of the most important design challenges faced during their design and production. Second, the testing of the final historical game in a primary school is described, analysing the way in which it contributed to foster the learners'/players' understanding of the defined historical period.

\section{The making of a historical game}

The making of a fully functional video game, even at a prototype level, can be a daunting task for a single developer/researcher such as myself. As complex digital artefacts, the production of any video game to an industry-standard level typically involves teams of highly specialised professionals who in some cases work for years before their product is released to the public. Needless to say, this level of production was impossible in the context of this research. Therefore, one of the most important challenges at the beginning of this project was to carefully align the development efforts to the research questions that needed to be explored while realistically assessing my personal expertise and limitations to conduct a project of this type. 
With a professional background and experience in games design and development, writing computer code and producing decent game art were not barriers, but professional knowledge and experience to critically evaluate my design ideas from a historical or educational perspective were.

In order to overcome this limitation, plans were put in place to share thoughts and to discuss the project at different stages with a number of specialists - historians, archaeologists and history educators - who became pivotal in the analysis of each one of the games produced. Built on iterative cycles of production, play-testing and evaluation, the games' main objective was to serve as 'thinking tools' (Eladhari and Ollila 2012,394), which would allow me to gain a better perspective of the issues involved in designing and using historical games in educational settings.

Fortunately for this project, game development technology has advanced spectacularly in the last decade, greatly facilitating the making of video games. Led by companies such as Unity and Unreal, game technology providers have made a concerted effort in lowering the budget and skills required to produce original games, providing a set of tools enabling independent developers, and even people with no development experience at all, to produce games previously only within reach of big AAA game studios. Along with these tools, communities of developers have grown organically in the last years, with forums, wikis and marketplaces where code, game art and other assets can be easily acquired and integrated into new projects. Armed with these new tools and community spaces of game creation, new design concepts and experiments can be quickly assembled and put to the test, contributing to the understanding of the field in a way that was difficult to do so before.

\section{The Anglo-Saxon village simulation}

As mentioned, the content of the game was defined as the Anglo-Saxon period of British history, a period that in general does not receives an adequate level of attention in primary and secondary schools, resulting in a significant proportion of students leaving their formal education with little or no knowledge of that particular time (Houghton, 2016). After defining the historical context of the game, the next design decision regarded the definition of the aspects where the game would put an emphasis on. What this game will be about? After some initial considerations, it was decided to centre the game on the representation of everyday life. For Crawford (2009), the transition from the late Romano-British to the Anglo-Saxon period was marked by a distinct change in the settlement patterns. At their arrival, Germanic tribes did not occupied old Roman cities, but preferred to live in 'small, self sufficient, localised farming communities with no evidence of complex hierarchies or administrative systems' (Crawford 2009, 4). Following this interpretation, the first application built to explore the representation of Anglo-Saxon life in game form consisted in an interactive simulation of an early Anglo-Saxon village.

For the building of the interactive simulation, the archaeological site of West Stow, in West Suffolk, was chosen as the main reference. The archaeological research conducted in this site gives evidence of early Anglo-Saxon occupation from AD420 to AD650, and has been thoroughly re- 
searched since 1976, combining the excavation of the site with experimental archaeological methods including the reconstruction of buildings and the scientific re-enactment of agricultural and productive processes. Along with the study of scientific articles and publications about the site archaeology, it was considered important to complement the information from these sources with the more direct approach of visiting and documenting in-situ the spatial configuration of the buildings, materials and construction details, all very important information for the virtual reconstruction of the site.

Following an Agent-Based Modelling (ABM) approach, the environment of West Stow was reconstructed through an hexagonal grid, over which a series of agents, representations of human and non-human agents, were introduced. As the application ran, these agents move busily through the hexagonal environment carrying on with their everyday activities. At the same time, a frenzy of numbers on the screen showed the internal variables of the system as they were re-calculated by the computer on each timeframe.

Both in its structuralist functioning and its explorative mode of interaction, the Anglo-Saxon village simulation can be seen as an example of a microworld, the educational use of educational technology developed in the 1960s by the mathematician, computer scientist and educational theorist Seymour Papert (1987). In a nutshell, microworlds provide an interactive context where learners can 'explore or manipulate the logic, rules, or relationships of the modelled concept, as determined by the designer' (Hogle 1995, 4). Notwithstanding its simplified construction, this first prototype provided an advantageous standpoint for the procedural exploration of everyday medieval life. By providing access to the variables governing the system the application allowed its users to play with its internal model, visualising in real time the consequences of making any change to the system. In this way, the simulation made it possible to experiment with hypothetical scenarios and to draw important conclusions, such as the minimum amount of land that an Anglo-Saxon family needed to survive or the consequences that sudden environmental changes would have for the village. Seen as a form of procedural rhetoric (Bogost 2010), the application built a strong case for a deterministic interpretation of history and eloquently expressed the fragility of life in Anglo-Saxon time. This was demonstrated by the fact that even a slight deviation of an ideal set-up in the simulation, most of the time, ended up having catastrophic effects.

As the dramas of medieval life unfolded in the microworld's screen, however, the application's limitations to connect empathically with characters from the past, which in the prototype consisted only in small and inexpressive icons, became evident. The educational potential of the application resided in its quantitative structuring, but, as the game designer and theorist Gonzalo Frasca (2001) argued, such an approach does not lend itself so well to the representation of social and personal issues, where meanings cannot be niftily translated in mathematical formulas. With regard to these issues, I would argue that history exceeds the representational capacity of the microworld. Even for Braudel, one of the most prominent structuralist historians, the analysis of human processes almost always ended up in his writings focusing on understanding people rather than structures (Skodo 
2010). In consideration to these issues, and to do justice to the multi-dimensional nature of history, it was considered necessary to represent the people from the past - with their individual struggles, motivations, values and modes of thought - as something more than mere sets of numbers running in the screen.

\section{From simulation to game}

Following the critical review of the Anglo-Saxon microworld, a second iteration of the historical game was built. The design goals defined for this version were ambitious. First, the game should give players access to a historically accurate representation of the Anglo-Saxon world, granting the exploration of the physical landscape of early medieval England, with its representative buildings and objects of cultural significance. Second, it should communicate how people lived at that time, encouraging players to analyse everyday life from multiple perspectives, gaining insights into its historical significance, change and continuity, cause and effect. Third, the game should be capable of bringing players inside the social environment of Anglo-Saxon Britain, displaying a world populated by agents capable of expressing social and cultural patterns of interaction with other agents and the virtual environment. Fourth, the game should convey historically based narratives of the chosen period, communicating evidence-based historical information while also allowing players to participate in the construction of a non-linear storyline. Lastly, the game needed to be engaging and fun, driving players to spend a significant amount of time, cognitive effort and emotional investment in relating meaningfully and effectively with the game systems and narratives.

[Fig. 1: Screenshot of the Anglo-Saxon historical game]

\section{Historical games and violent conflict}

Historical and archaeological sources reveal that the Anglo-Saxon period was a time of great change in Britain, where the physical character of the people, language, social and cultural institutions were radically transformed. This process, however, has been remarkably difficult to be studied due to the general lack of primary historical sources available. For the most part of the 20th century it was assumed that this was a violent time in which the Germanic invaders raided the land killing, enslaving and driving away the Romano-British population out of their lands. This narrative, however, has been called into question in the light of more recent historical and archaeological interpretations. Although there is little doubt that the clash between Anglo-Saxons and the Romano-British was at times violent, there is also evidence of more subtle and complex processes of integration between both groups. In this respect, Härke (2011) distinguishes between three different patterns of integration: First, the cohabitation of Germanic and native populations living in close contact but with social dynamics of apartheid keeping both cultures separate from each other. Second, a 'warband model' represented by an influx of male warriors from Germanic tribes taking control of a local community and marrying native woman, and, finally, an 'elite transfer' model with a small group of immigrants replacing the native population elite and taking control over the ruling of the land. 
To put an emphasis on these processes, it was decided to centre the game on the representation of everyday life, avoiding the representation of violent conflict. In this sense, the game is in contrast with most of the historical games based in this period, in which combat mechanics are designed to be the primary form of interaction. The reasons for this are not difficult to fathom: as Salen and Zimmerman $(2004,80)$ stated, games are primarily systems of conflict, naturally inclined to represent any determined situation as an opposition between forces, a 'contest of powers'. This representational bias typically tends to antagonise sides in a zero-sum schemes of competition for one or more winning conditions. As a result, games naturally lend themselves to the simulation of violent conflicts, with historical video games being no exception to this trend. The representation of alternative social dynamics, however, requires a completely different - undoubtedly more sophisticated - design arrangement.

From a different perspective, the design decision of avoiding the representation of violent conflict within the game can be seen as controversial. Historical and archaeological research draws a picture of a changing social landscape where violence cannot be ruled out as a major socio-cultural shaping process. In this sense, a game deprived of any representation of violence can be rightfully branded as 'inauthentic' or ideologically biased in favour of the hypothesis of a pacific process of assimilation between Anglo-Saxons and Britons. Although this argument strongly suggests that combat should be part of the game's experience, the potential negative effects of this form of interaction cannot be overlooked. As Stuart (2013) comments: 'in games, violence is often the core feedback loop, the defining mechanism. Everything gets swallowed up into this dysfunctional vortex.' Even first-year archaeology students, as Champion $(2008,2015)$ remarks, often tend to relate with virtual game-like archaeological reconstructions following destructive and violent patterns. While not claiming that combat and historical learning are mutually exclusive categories, after considering the impact of violent game-interaction for the educational goals of this project, I decided to remove combat completely from the game-playing experience.

\section{Representing the Anglo-Saxon landscape and way of life}

According to historical and archaeological interpretations, much of life in early Anglo-Saxon time centred around finding the means to survive in the challenging environment of post-Roman Britain. To sustain themselves, early Anglo-Saxons dedicated most of their time to collecting and/or producing of food and drink, a time-consuming occupation that determined their lives 'both at the basic level of survival and at the level of everyday social interaction' (Crawford 2009, 93). Central to this process was the intimate understanding of their environment. As Crawford $(2009,93)$ explains:

A detailed knowledge of the resources of the landscape, and an understanding of how to exploit these resources, was crucial to the survival of the early Anglo-Saxons [...] Integral to that process was the knowledge of how the landscape worked - where the best soils were, where the water could be found (and whether the source of water was reliable), what the best crops to grow were, where the land would not support farming and where the best hunting was. 
Under these terms, the gameplay and narrative context of the game seemed naturally aligned with the conventions of the survival game genre, ${ }^{1}$ a form of gameplay that puts the player in a challenging environment in which the ultimate goal is to live for as long as possible. Subsistence depends on the decisions taken, demanding an in-depth knowledge of how the virtual environment functions and its resources.

The digital translation of the subtle layers of meaning from inhabited worlds to the computer, where complex processes and interactions between humans and the environment have somehow to be condensed into computer code, always involves a level of abstraction. For the algorithmic synthesis of these concepts, the anthropologist Ingold's analysis of inhabitation provided useful perspectives. For Ingold $(2000,77)$, the relationship between people and environment is two-fold:

According to the received categories of archaeological and anthropological thought, there are basically just two ways of procuring a livelihood from the natural environment, conventionally denoted by the terms collection and production.

While the collection of resources from the environment seemed relatively straightforward to implement in the game, for example using a 'pick-up' gameplay design pattern, the production of resources required further thought. As Ingold (2000) explains, the process of production, or 'growing things', should not be misunderstood with the process of making, where humans are set to transform nature instead of following its ways.

The farmer, and for that matter the raiser of livestock, submits to a productive dynamic that is immanent in the natural world itself, rather than converting nature into an instrument to his own purpose [...] in clearing fields, turning the soil, sowing, weeding, reaping, pasturing their flocks and herds, or feeding animals in their stalls - are assisting in the reproduction of nature, and derivatively of their own kind (p. 81).

Conceiving the relationship with the environment under these terms, the game had to implement mechanics for the procedural representation of the processes of collecting, producing and making. For the translation of these processes into the world of the computer, a conceptual framework able to guide the efforts of representing the intricate relationships between people and material world was very much needed. Ultimately, the framework for this definition came from Gibson's (2015) theory of ecological perception and more specifically the concept of affordances, a signifier for the possibilities of action of an agent in a particular environmental setting. Usually described as 'ables', as in 'catch-able', 'clim-able' of 'eat-able', a key part of the concept resides in that it is always relative to the agent, not an objective property of the environment. An affordance describes the potential that an agent has to interact with the environment, for good or for ill. Following the

\footnotetext{
${ }^{1}$ The survival game genre is credited to Sami Maaranen, a Finnish game developer who in the early 1990s developed, almost entirely on his own, a groundbreaking game that set the foundations of the genre. The game, named Unreal World (Maaranen, 1992), enabled players to take the role of a solitary Iron Age man in his attempt to survive the severe environment of ancient Finland. In basic terms, the survival genre puts the player in a threatening environment in which the ultimate goal is to survive for as long as possible. Subsistence depends on the decisions he/she takes, and how intimately he/she gets to know his/her world. This type of game emphasises a player's freedom, setting to that effect large worlds open for exploration.
} 
same logic, gameplay can be described as a process where players perceive, act and transform the affordances related to game systems or to other players (Linderoth 2011) and forms an extremely useful approach to study historical games (Chapman 2013).

Structuring the virtual historical world as an environment for the exploration of affordances, the player's interaction within it was organised as a sequence of steps. In a first step the player's embodiment in the game world, an Anglo-Saxon free peasant or ceorl, was developed to allow the player to navigate and explore its surroundings. In the computer interface, the real-world action of 'looking around' was replaced by the simultaneous actions of scanning the screen and displacing the mouse over the objects in proximity. Likewise, the action of 'focusing the attention', which in the real world would involve getting closer, and if deemed necessary grabbing and examining objects of interest, in the virtual world was translated to by the action of mouse-clicking. Upon doing this, the manifested intention of knowing more about the selected object was answered by a pop-up window, where the computer gave contextual information about it and declared its affordances through a list of clickable buttons. Upon the selection of one of the object's affordances, the computer then proceeded to simulate its agency, simulating what the object was able to do by implementing the relevant changes in the game's internal model and immersive world.

\section{Representing social life}

Since the 1980s, commercial game studios have dedicated a great deal of resources in creating massive open game environments, developed to sustain the illusion of densely populated worlds. Examples of these worlds can be seen in video games franchise such as Assassin's Creed, and Grand Theft Auto. In all of these games we are able to walk around characters with different identities and even engage in meaningful conversations with some of them. These games are able to transport us to alternate worlds that seem to be 'alive'. After a few hours of play, however, the illusion becomes difficult to sustain. In spite of their graphic realism, with their scripted dialogue lines and predictable behaviours, virtual characters sooner than later become nothing but animated mannequins with which we cannot relate meaningfully, or feel some form of attachment. As Farrow and Iacovides (2013) and Isbister (2016) argue, emotional involvement in a game does not reside so much in the immersive and mimetic properties of the medium, but in its capacity to drive players to reflect on the effect of their decisions with an elevated sense of responsibility. To explain this argument we can take as an example the film Castaway (Zemeckis 2000). In this film, a sole survivor from a plane crash finds himself stranded in a deserted island where, finding it impossible to live in isolation, starts to talk with a volleyball ball. Although the protagonist is conscious of the falsehood of the situation, he nevertheless develops a strong bond with the inanimate object, led to a large extent by his urgent need to care for someone other than himself. In my view, we (or most of us) are programmed to care and take responsibility for others, and on this proclivity rather than on high levels of immersion or realism we can find the key for the creation of inhabited historical worlds. 
With these ideas in mind, a series of non-player-characters (NPCs) were implemented in the Anglo-Saxon game. These characters had no virtual representation in the three-dimensional game world, but were developed to interact with the player through text-based conversation systems accessible through the game's graphic user interface (GUI). In alignment with the archaeological interpretations on the social composition of early Anglo-Saxon settlements, which regard them as primarily composed by small family units (Crawford 2011), it was decided to add two characters related to the player's avatar by family bond: a small son named Wilburg and a teenage daughter named Eadgyð. These virtual 'family members' were programmed to take care of various everyday tasks (fetching water, cooking, etc), but they had to be looked after by the player, who had to comply with the 'responsibility' of providing them with the basic means of subsistence. Later on, during the development of the prototype a third character, Bryn the Romano-British slave, was added to the game. The purpose of introducing this new character was to provide the context for the exploration of the cultural clashes between the arriving Anglo-Saxons and the original Romano-British population.

\section{Testing the Anglo-Saxon game in a primary school classroom}

After a sequence of iterations where different versions of the game prototype were developed in cycles of development, testing and evaluation, a final version of the Anglo-Saxon historical game was tested in a pilot study within the context of a primary school. The targeted group for the pilot testing was a Key Stage 2 Year 5 class (9-10 years old) attending a small primary school from Cheshire, UK. Following and integrated curriculum, the primary school used Anglo-Saxon and Viking history as a driver to engage in all subject areas studied by the group. At the time of conducting the evaluation, the group had already studied the Anglo-Saxon period from multiple perspectives through a variety of learning activities.

In order to evaluate the game prototype's design and pedagogical value, the pilot study adopted a pre-post testing methodology. This approach, commonly used in educational research, was employed to provide evidence of the effects or changes caused by a particular educational intervention. In general terms, it involves the gathering of measurable data concerning an outcome of interest before the administration of the intervention, followed by a post-test measuring the changes that occurred on the same measure of interest (Bell 2010). The children were asked in the first session to draw a picture representing life in Anglo-Saxon time. In the sessions that followed, the game was played by them, collecting in-game data from their actions and navigation. Lastly, children were asked to draw a final picture communicating their ideas about the historical period. In both the first and final drawing sessions, mini-interviews were conducted with students, following a 'talk and draw' research approach (Prosser 2007, 22).

The use of drawings was selected primarily due to the children's age. Visual methods such as these are recommended by different authors as an advantageous method to research children's perceptions, knowledge, attitudes and beliefs. Kitahara and Matsuishi $(2008,10)$, for example, state 
that drawing 'tends to recount far more things to the reader than language'. At a young age, children have not yet developed the ability to articulate abstract linguistic expressions, but in most cases feel comfortable resorting to symbolic means of communication such as drawing to communicate their thoughts. Also, this form of gathering data can be augmented by engaging in informal conversations while the children draw. These conversations usually take the form of unstructured interviews where the researcher asks the children to expand on the ideas, narratives and mental processes involved in the creation of the drawing, which may not be so evident when looking only at the final children's creations.

\section{Drawing and playing as dramatic engagements with the past}

Psychological research on early childhood shows that children innately use narrative engagements such as drawing, painting, and three dimensional play as means to understand the world around them, both factually and emotionally (Ahn \& Filipenko 2007). This observation certainly proved to be true while testing the Anglo-Saxon game. In both their drawings and playing actions, children engaged with an imagined past positioning themselves as active agents, assuming a protagonist role within the representations. It is fair to say that in the game as well as in the drawings, children were their characters, importing their views about the functioning of the world to the situations recreated in the malleable canvas of the paper sheet or the algorithmic game world. From this perspective, the children's actions of drawing and game-playing the past can be considered as spontaneous exercises of re-enactment, of 'being-in-the-world' (Heidegger 2010), which revealed as much about their personal identities, lives and world views in the present as about their conceptions of an imagined past. When consulted about the origin of their historical preconceptions, children referred not just to learning activities conducted in the classroom, but also to media contexts outside the school (e.g. 'the internet')

As an illustration of this argument, consider this extract of a conversation with one of the participants as he worked on his pre-playtest drawing: (Bollignton Cross Primary School, October 14th 2016, Ph.D project: Gaming the Past: Designing and Using Digital Games as Historical Learning Contexts,)

Interviewer: [Pointing to a part of the student's drawing] Is this your house?

Student: Yes.

Interviewer: Why is this your house?

Student: Because this is the best house I drew in this picture.

Interviewer: So you would be living in the best house?

Student: Yes.

Interviewer: Why? Why you would be living in the best house?

Student: Because, I'm thinking that I am respected... Because, food was an important thing for the Saxons [...] there was quite a bit but it was hard to get... and if you were a good hunter that 
means you would have more money from selling the food that you caught... and if you had family you were able to keep your family safe.

In this particular case the child composed a drawing where his personal identity, his Anglo-Saxon avatar functioned as an 'externalisation' (Bolton 1979) of both his objective and subjective assumptions of the past. From an objective perspective the subtext of the drawing evidences the child's efforts to come up with the 'rules' defining 'what it was like to be' a character from the past. In this externalisation ideas about the Anglo-Saxon world, such as 'hunting was a valuable skill', go hand in hand with personal ideologies of fairness, such as 'the best hunter deserved the best house in the village'. The child, however, is not imagining a situation with just any identity being the protagonist. As he is portraying no one other than himself in the picture, we need to recognise also the subjective meanings, conscious or not, at play. In this case, through his drawing the child might well be implying that: 'I am (or want to be) the best', or 'I want to be recognised for the things I'm good at'.

As Heathcote (1991) and Bolton (1979) maintain, the dramatic engagement with a determined educational content, looking at reality through the fantasy of being somebody else, can be a powerful way to explore 'below the surface', the deepest levels of meaning implied in a particular situation. In the same way as in the aforementioned example, children also gave evidence through their drawings and comments of assumptions about the hardships of everyday life ('life was very hard'), violence ('they used to fight a lot and people got hurt a lot') and social life ('sometimes they met on campfires to sing stories and tell stories') in Anglo-Saxon time. While playing the game, these assumptions were very much present, and in some cases were reinforced or challenged by their experiences within the game. In the remaining sections, each one of these themes will be explored in further detail.

\section{Surviving the Middle Ages}

Both in their pre-test and post-test drawings and comments, children coincided in their views of Anglo-Saxon everyday life as a constant and difficult struggle for self-preservation. In this sense the core gameplay of the game centred on the conventions from the survival genre, were in line with the children's previous knowledge and assumptions about life in the early medieval age. Within the game children had to take care of themselves and their family members, making sure to produce enough food and drink for them to carry on with their lives. This goal was primarily achieved by the performing of 'tasks', the 'constitutive acts of dwelling' carried out by a 'skilled agent in an environment, as part of his or her normal business of life' (Ingold 2000, 195). Mimicking the execution of tasks in the real world, this level of gameplay was structured in repetitive patterns, representing a level of historical re-enactment which Braudel (1985) identified as 'material life'; the unconscious routines devoted to daily subsistence that in their repetition become a generality or rather a structure. 
As evidence of the way in which the game's core gameplay emphasised the argument of life as a struggle and reinforced the children's assumptions aligned with this view, the children's representations of everyday tasks increased significantly in their drawings and accounts of life in Anglo-Saxon time. While relatively few pre-playtest drawings included tasks or activities representative of medieval everyday life, in post-playtest drawings their presence became considerably more prevalent, with a greater range of activities and level of detail included in the representations. Also, the children's appreciation of tasks seemed to become more procedurally orientated, communicating in some instances a level of understanding and strategic thinking not observed in the first sessions. As examples, some children remarked on the importance of building their houses close to sources of water because it 'run out quick', or recounted the slaughtering of all their sheep as a poor decision, reflecting in hindsight how this left them with no source of food for the upcoming winter's scarcity.

Swords and axes: Life was violent

Violence appeared as a recurrent theme for children while imagining the past in Anglo-Saxon time. In alignment with the way in which the medieval period has been generally portrayed in films and TV, for children Anglo-Saxons 'used to fight a lot'. While in some cases the period was seen as generally turbulent, in other cases children made specific references to the groups and factions engaged in historical conflicts, antagonising Anglo-Saxons against 'the Romans' or 'the British' in a bloody conflict for power and land. According to this narrative, the game exclusion of combat mechanics was considered as a design flaw by most children, made explicit in their comments after playing the game.

In hindsight, instead of excluding the representation of violence entirely, the game could have been designed to contrast it against other forms of social interaction. As archaeologists emphasised during the game's review sessions, this was a very particular time in British history where cultural groups very different from each other were gradually learning to live together. Without underestimating the occurrence of violent clashes, different groups and individuals could have socialised in contrasting ways, not different in many respects from the divergent patterns of interaction that we find in modern multicultural societies. In this way, potentially problematic situations such as 'British woman marrying an Anglo-Saxon' or 'Anglo-Saxon buying things from a Roman-Briton', once presented to the player, could have been designed to offer multiple paths of solution, foregrounding the tensions, conflicts and contradictions that characterised the intercultural encounters of the Anglo-Saxon time.

\section{Campfires and halls: Life was social}

In their drawings as well as in their interviews, children commented recurrently on the importance of social life for early Anglo-Saxons. According to their ideas about the medieval world, it was customary for people to periodically come together to 'have stories', 'meeting [other] people' and even 'singing songs' around open campfires or within wooden halls. Although the game made it possible for children to recreate these objects and built structures within the world immersive interface, the 
lack of social presence in the game-world was regarded as another major design flaw. For most children, it was simply not enough to interact with characters through text-based dialogues; it was also needed to have a world where they could 'see everyone'.

In part due to this lack of a tangible presence of characters in the game world interface, for many children it was difficult to establish meaningful connections with their virtual 'family members'. Instead of connecting empathetically with them, many children regarded them more of a 'hassle', skipping their dialogues, refusing to spend time feeding them, and ignoring the screen messages alerting them to their proximate starvation. In an exceptional case, however, a particular character narrative succeeded in 'hooking' players. In this narrative, Wilburg, the character posing as the player's son, asked his father (the player) not to be sold as a slave in the not-unlikely situation of crops failing to produce. After reading this dialogue sequence, many children reacted with surprise, demanding the teacher to explain whether it was true that Anglo-Saxon parents eventually gave up their children into slavery. In the 'teachable moment' that followed the topic of slavery was discussed extensively; its meanings, implications and current status in the modern world explored in an open after-play discussion.

Driving from this experience, it is possible to argue that the historical game prototype worked at its best when it engaged players effectively with certain aspects of the past. Where other character narratives were simply ignored or quickly forgotten, Wilburg's drama succeeded because it successfully challenged the children's conceptions about the functioning of the world, and, appealing to their feelings, it also created an urgent need for resolution. For the psychologist Howard Gardner (2011), this type of learning situation can be described as a 'Christopherian encounter'. Just as Christopher Columbus set sail to the West to put his geographical ideas to the test, Gardner argues that children's misconceptions and naive forms of understanding, which have been demonstrated to be incredible persistent, can be tackled by presenting them with conflicting scenarios where the contradictions and disjunctions in their thinking become exposed.

\section{Conclusion}

This chapter presented an overview of the development and testing process of an experimental video game based on Anglo-Saxon Britain. Following an iterative design process, an initial simulation of an Anglo-Saxon village simulation was produced. This simulation served as the basis for the construction of an immersive historical game, which in a later stage was integrated and tested within the history curriculum of a primary school. The collection of data before and after playing the game revealed that children's preconceptions about the past were interrogated by their experiences within the game, resulting in some cases in dissonances that were productively exploited in postplay open discussions.

For the children that participated in the evaluation, the game's emphasis on survival was in line with their ideas about everyday life in the Anglo-Saxon age, generally judged as a difficult time to 
live on. The lack of violent gameplay, however, was regarded as an inauthentic representation of this period. Despite the tendency of violent or combat game mechanics to overshadow other forms

of gameplay, violence could have been implemented in the game as one of the multiple ways of dealing with problematic situations, emphasising the short and long term consequences of each alternative path of action. In addition, the game's lack of interactive non-player characters was also in opposition with the children's preconceptions, where Anglo-Saxon life was imagined as highly social. Despite that the simulation of social interaction through text-based narratives in general failed to engage children empathetically with the game characters, in one case the drama of one of their virtual 'family members' succeeded in connecting affectively with most children, becoming a powerful teachable moment.

\section{Bibliography}

Ahn, J. and Filipenko, M. "Narrative, imaginary play, art, and self: Intersecting worlds." Early Childhood Education Journal 34, no. 4 (2007): 279-289.

Bell, B. "Pretest-Posttest Design." In Salkind, Neil J. Encyclopedia of Research Design. Thousand Oaks, CA: SAGE Publications, Inc., 2010. doi: 10.4135/9781412961288.

Bogost, Ian. Persuasive Games: The Expressive Power of Videogames. Cambridge: MIT Press, 2010 .

Bolton, Gavin. Towards a Theory of Drama in Education. Hong Kong: Longman Group, 1979.

Braudel, F. Civilization and Capitalism, 15th-18th Century, Vol. I: The Structure of Everyday Life. Berkeley, Los Angeles: University of California Press, 1985.

Caillois, Roger. Man, Play and Games. Urbana and Chicago: University of Illinois Press, 1961.

Champion, Erik. "Game-Based Historical Learning.” In Handbook of Research on Effective Electronic Gaming in Education, edited by Richard E. Ferdig, 105:219-34. Florida USA: Information Science Reference, 2008. doi:10.1093/jnci/djs562.

Champion, Erik. Critical Gaming: Interactive History and Virtual Heritage. Surrey, England: Ashgate Publishing, Ltd., 2015.

Chapman, Adam. "The Great Game of History: An Analytical Approach to and Analysis of the Videogame as a Historical Form." PhD diss., University of Hull, 2013.

Crawford, Chris. The Art of Computer Game Design. New York, NY: McGraw-Hill, Inc, 1984.

Crawford, Sally. Daily Life in Anglo-Saxon England. Oxford/Wesport, Connecticut: Greenwood World Publishing, 2009.

Crawford, Sally. Anglo-Saxon England. Oxford: Shire Publications Ltd., 2011.

Eladhari, M. P., and E. M. I. Ollila. "Design for Research Results: Experimental Prototyping and Play Testing." Simulation \& Gaming 43, no. 3 (2012): 391-412.

Farrow, Robert, and Ioanna Iacovides. "Gaming and the Limit of Digital Embodiment." Philosophy \& Technology 27, no. 173 (2013): 221-33. 
Frasca, Gonzalo. "Videogames of the Opressed: Videogames as a Means For Critical Thinking and Debate." Georgie Institute of Technology, 2001.

Gardner, Howard. The Unschooled Mind: How Children Think and How Schools Should Teach. Hachette UK: Basic Books, 2011.

Gibson, James J. The Ecological Approach Visual To Perception. Classic ed. New York, London: Taylor \& Francis Group, 2015.

Heathcote, D. Collected Writings on Education and Drama. Evanston, Illinois: Northwestern University Press, 1991.

Heidegger, Martin. Being and Time. Translated by Joan Stambaugh. Albany: State University of New York Press, 2010.

Hogle, JG. Computer Microworlds in Education: Catching up with Danny Dunn. ERIC Clearinghouse, 1995.

Houghton, R. "Where did you learn that? The self-perceived educational impact of historical computer games on undergraduates." Gamevironments 5 (2016): 8-45.

Ingold, Tim. The Perception of the Environment. London Routledge. London and New York: Routledge, 2000. doi:10.1207/S15327884MCA0902.

Isbister, Katherine. How Games Move Us: Emotion by Design. Edited by Jesper Juul, Geoffrey Long, and William Uricchio. London, UK and Cambridge, MA: The MIT Press, 2016.

Kinser, Samuel. "Capitalism Enshrined : Braudel 's Triptych of Modern Economic History." The Journal of Modern History 53, no. 4 (1981): 673-82.

Kitahara, Reiko, and Takeshi Matsuishi. "Research on Children 's Drawings," 2008, 10-14.

Linderoth, Jonas. "Beyond the Digital Divide : An Ecological Approach to Game-Play." Transactions of the Digital Games Research Association (ToDIGRA), 2011, 1-17.

Papert, Seymour. "Microworlds: Transforming Education.” Artificial Intelligence and Education 1, no. March (1987): 79-94.

Prosser, Jon. "Visual Methods and the Visual Culture of Schools." Visual Studies 22, no. 1 (2007): 13-30. doi:10.1080/14725860601167143.

Skodo, A. "Fernand Braudel and the Concept of the Person." Historisk Tidskrift 130, no. 4 (2010): $2-24$.

Stuart, Keith. "The Last of Us, Bioshock: Infinite and Why All Video Game Dystopias Work the Same Way.” The Guardian, July 2013. https://www.theguardian.com/technology/gamesblog/2013/ jul/01/last-of-us-bioshock-infinite-male-view.

Salen, Katie, and Eric Zimmerman. Rules of Play: Game Design Fundamentals. Cambridge, Massachusetts and London, England: MIT Press, 2004.

Zemeckis, Robert. Castaway. United Kingdom: 20th Century Fox and Dreamworks Studios, 2001. 